\title{
Plagio en publicaciones científicas en el pregrado: experiencias y recomendaciones
}

\author{
Plagiarism in undergraduate \\ publications: \\ experiences and recommendations
}

$\mathrm{S}^{\mathrm{r}}$ Editor: La Revista Médica de Chile publicó ecientemente un artículo titulado «Ética de las publicaciones en revistas médicas». En él se presentan importantes ejemplos de infracciones cometidas por profesionales de amplia trayectoria ${ }^{1}$. Compartimos su preocupación por incentivar la capacitación en los procesos de publicación desde el pregrado $^{2,3}$. Se sabe que la ignorancia no exime de culpa, por lo que no es excusa ser un profesional joven o tener poco conocimiento en la materia cuando se deba enfrentar las consecuencias de una infracción en las normas de investigación o publicación.

Por otro lado, los ejemplos que expone ese artículo muestran que el tiempo que se tiene desarrollando investigación no evita transgredir los principios de ética, quedando demostrado que es más valioso poseer una sólida formación. Lamentablemente son pocos los cursos acerca del proceso de publicación científica que se imparten en el pregrado y menos aún sobre temas de ética en publicación ${ }^{3}$. Además, es frecuente encontrar diferentes niveles de plagio en los trabajos monográficos de los estudiantes de medicina ${ }^{4}$, donde el hábito de «copiar y pegar» no siempre es detectado y se le da poca importancia, así como traducir información de otras publicaciones haciéndolas aparecer como propias; esta situación contribuye a que el uso de ideas ajenas, o aun peor, de datos ajenos sin citarlos, sean vistos como algo «normal»y no punible.

Correspondencia a: Percy Mayta Tristán, Nicolás Dueñas 161, Urb. Stella Maris, Bellavista, Callao, Perú. Teléfono (511) 4536659. E mail: hampi sanfer@hotmail.com
La revista Ciencia e Investigación Médico Estudiantil Latinoamericana (CIMEL) es la única revista estudiantil indexada en la base de datos SciELO y es la máxima representante de la corriente actual de revistas científicas estudiantiles ${ }^{5}$, recibe trabajos de estudiantes de medicina de toda Latinoamérica y en este contexto -frecuencia de copia en trabajos estudiantiles- era muy probable que llegaríamos a detectar un caso de plagio.

A principios de este año recibimos una carta al editor de un grupo de investigadores que nos manifestaron su preocupación por un artículo publicado en CIMEL, en el que habían detectado el plagio de su propio estudio -publicado en una revista indexada- en partes del texto de la introducción y discusión. A partir de esta situación empezamos a indagar sistemáticamente indicios de plagio (Tabla 1), en los demás artículos recibidos y aquellos que estaban por publicarse. Este sistema de revisión adicional dio como resultado nuevos casos de plagio, al punto que tuvimos que retirar un artículo de imprenta por tener varios párrafos copiados y detener el proceso de revisión de otros.

Esto ha motivado que realicemos talleres de capacitación y cursos sobre redacción científica, tanto para el comité como para estudiantes interesados, en los que se incluye el tema de ética en publicación. Así mismo, hemos adoptado políticas editoriales para el manejo de estas situaciones empleando los flujogramas de trabajo del Committee of Publication Ethics (www.publicationethics.org.uk). Desde entonces, cuando se encuentra un caso de plagio en un manuscrito evaluado, se procede a enviar una comunicación a los autores en la que se les indica que han cometido una falta ética, se les brinda información al 
Tabla 1. Sistema de detección y manejo de casos de plagio propuesto en CIM EL

Paso 1. Identificación de párrafos con indicios de plagio:

a) Párrafos consecutivos con distintos estilos de redacción.

b) Conjunto de párrafos sin secuencia lógica.

c) Párrafos que citan artículos que no están incluidos en las referencias.

d) Párrafos que usan referencias de difícil acceso.

Paso 2. Búsqueda en Google - Google Scholar de párrafos sugerentes de plagio.

Se copia íntegramente el párrafo y es incluido sin « «en el buscador de Google y Google Scholar, luego se rescatan los documentos coincidentes.

Paso 3. Identificación del plagio.

Se seleccionan los artículos ubicados y se cotejan los párrafos coincidentes; se evalúa y se decide si existe plagio 0 no en el estudio.

Paso 4. Comunicación con el autor.

a) Si el plagio es sólo en la introducción y discusión, se le informa que ha cometido una falta ética, se brinda información adicional y se le solicita modificar el manuscrito evitando incurrir en plagio.

b) Si el plagio es en los materiales, métodos y resultados, se le informa el rechazo de su artículo por haber cometido una falta en la ética de las publicaciones científica, y se le brinda información.

respecto y se les solicita que procedan a modificar su manuscrito respetando las normas.

Es importante tener en cuenta que el papel del comité editorial de una revista científica no es el de sancionar o investigar profundamente los diversos tipos de faltas contra la ética en publicación, sino el de informar la situación a las instituciones de donde provienen los investigadores, siendo éstas las que deberán determinar la magnitud de la falta y las sanciones a aplicar, siempre teniendo en cuenta que la sanción no sea mayor a la falta cometida, ya que en muchos casos este tipo de situaciones generańa el rechazo inminente de sus futuros manuscritos ${ }^{6}$.

El reconocer la fuente de la información utilizada es una norma que no se debe olvidar, la falta contra esta norma se considera plagio ${ }^{6}$. No obstante, muchas de estas faltas son propias de la inexperiencia de los autores o un inadecuado conocimiento sobre las formas comectas de citación, más que muestras de mala fe o deshonestidad.

\section{REFERENCIAS}

1. Reyes H, Palma J, Andresen M. Ética de las publicaciones en revistas médicas. Rev Méd Chile 2007; 135: 529-33.

2. Reyes H. Honestidad y buena fe: dos pilares en la ética de las publicaciones biomédicas (Editorial). Rev Méd Chile 2007; 135: 415-18.

3. GutiérRez C, MaYta P. Publicación desde el pregrado en Latinoamérica: importancia, limitaciones y
Estamos conscientes de que nuestra labor como revista estudiantil es ante todo formativa, tanto para los miembros del comité como para los autores que contribuyen con la revista ${ }^{5}$, por ello consideramos importante que en las revistas de amplia difusión como la Revista Médica de Chile se aborden estos temas ${ }^{1,2}$. Así mismo, es necesario que las Facultades de Medicina incluyan estos tópicos en sus cursos sobre investigación. De igual manera, deben tomarse medidas para detectar y corregir los casos de plagio en las monografías o trabajos de los estudiantes de medicina, para que se dé una formación adecuada a los futuros investigadores de nuestros países.

\section{Verónica Rojas-Revoredo $^{1,2}$, Charles Huamaní1,2, Percy Mayta-Tristán ${ }^{2,3}$. \\ ${ }^{1}$ Estudiante de Medicina, Universidad Nacional Mayor de San Marcos. Lima, Perú. ${ }^{2}$ Comité Editor, Revista Ciencia e Investigación Médica Estudiantil Latinoamen- cana (CIMEL). ${ }^{3}$ Instituto Nacional de Salud. Lima, Penú.}

alternativas de solución. CIMEL 2003; 8: 53-60.

4. Bilic-Zule L, Froovic V, Turk T, Azman J, Petrovecki M. Prevalence of plagiarism among medical students. Croat Med J 2005; 46: 126-31.

5. MaYta P. Revistas científicas estudiantiles en Latinoamérica. Rev Méd Chile 2006; 134: 395-97.

6. Word Association of Medical Editors (WAME). List serve discussions: How to Handle Plagiarism without Destroying the Author. Disponible en: www.wame.org/wame-by-topic [consultado el 18 de junio, 2007]. 